Article

\title{
Modifiable Campus-Wide Appraisal Model (MOCAM) for Sustainability in Higher Education Institutions
}

\author{
Yusuf A. Adenle ${ }^{1,2, *}$, Edwin H. W. Chan ${ }^{1,2}{ }^{\oplus}$, Yi Sun ${ }^{1}\left(\mathbb{D}\right.$ and C.K. Chau ${ }^{2,3}$ \\ 1 Department of Building and Real Estate, The Hong Kong Polytechnic University, Hong Kong 99077, China; \\ bsedchan@polyu.edu.hk (E.H.W.C.); yi.sun@polyu.edu.hk (Y.S.) \\ 2 Research Institute for Sustainable Urban Development (RISUD), The Hong Kong Polytechnic University, \\ Hong Kong 99077, China; chi-kwan.chau@polyu.edu.hk \\ 3 Department of Building Services Engineering, The Hong Kong Polytechnic University, \\ Hong Kong 99077, China \\ * Correspondence: yusuf.a.adenle@connect.polyu.hk
}

Received: 16 July 2020; Accepted: 19 August 2020; Published: 22 August 2020

\begin{abstract}
Institutions of higher education across the globe have commenced the appraisal of their sustainability performance via the utilization of various existing campus sustainability assessment tools. A comprehensive review of these existing tools reveals insufficient utilization of weighting methods and theoretical approaches that allow for the monitoring, review, and enhancement of the appraisal process and tools. Social media and spatial-based indicators usage are also deficient in the existing tools. This paper addresses these research gaps and develops a Modifiable Campus-wide Appraisal Model (MOCAM) for a comprehensive spatial-based information and assessment framework for policymakers, local authorities, and campus planners in countries with unknown campus sustainability status. In this model, the specific, measurable, achievable, relevant, and time-bound (SMART) approach was utilized to identify environmental-dimension indicators with campus-wide and spatial-based attributes. The Twitter social media platform, Elastic stack, and Python Library were used for the extraction and analysis of local stakeholders' user-generated content for the identification of localized indicators. The analytic hierarchy process was used for the determination and analysis of the attribute level of importance and weights. The model also broadens the application of symbolic interactionism by translating it from the predominant field of social science to sustainable campus appraisal.
\end{abstract}

Keywords: social media; symbolic interactionism; AHP; Nigeria; sustainability assessment tools

\section{Introduction}

The 1972 Stockholm Conference was amongst the first international approaches toward sustainability, in which strategies for preventing the challenges endangering the existence of humans were initiated [1]. Thereafter, in 1987 the most widely accepted and used definition of sustainable development as "the need of the present generation without compromising the ability of the future generation to meet their needs" was published in the Brundtland Report [2]. However, several approaches, such as that of the United Nations Educational, Scientific, and Cultural Organization (UNESCO) [3], to ensuring sustainable development actualization have been proposed. A decade for the initiation, incorporation, and execution of education for sustainable development was also announced by the United Nations (UN) [3]. This UN declaration mandates higher education institutions (HEIs) to adopt the concept of sustainability in their operations, teaching, research, and appraisal. 
The establishment of a sustainable society can be enhanced with the involvement of HEIs in awareness creation, knowledge dissemination, and skill acquisition [4]. More so, the fact that they (i.e., HEIs) nurture and train future generations through teaching, academics, research, and management and community engagement programs will aid them in designing, planning, and implementing the development of sustainable human societies. Lukman and colleague posited that the actualization of a sustainable global village is achievable via the effective publicity of sustainability practices by HEIs [5]. Additionally, HEI students can easily implement the practices of sustainability in society by experiencing these practices within their HEI campuses before graduating [4]. As such, the implementation of sustainability initiatives, programs, and plans encompassing all-round activities and operational functions should be carried out by HEIs.

In the global context, declarations such as the Barcelona and Talloires can be attributed as foundations in realizing the state of affairs for sustainability performance appraisal at HEIs. In addition to these international declarations, campus sustainability appraisal (CSA) tools also assist in achieving the actualization of sustainability undertaking and higher quality of life (QOL) attainment [6] in HEIs. Several reviews of the various CSA tools have been conducted in the extant literature [7-12]. The reviews reveal that after several declarations, UN mandates, and the establishment of numerous CSA tools, limitations and knowledge gaps that demand the attention of scholars, practitioners, and policymakers in campus planning and appraisal still exist. Alshuwaikhat and colleagues observed the lack of the spatial dimension of HEI campuses in the framework of the existing CSA [13]. Likewise, the exploration of social media coverage practices in CSA tools has not been extensively covered, despite social media's ability to disseminate and monitor sustainability indicators.

Though social media in campus-related articles have been widely examined and discussed, social media research is still in its infancy. Another challenge confronting researchers conducting CSA is the formulation of a theoretical basis that serves as the foundation for organizing and illustrating the relationship that exists between HEI CSA and the identification of preferred campus sustainability indicators based on social media data. Detailing explanations, theoretical frameworks, or philosophical approaches concerning this challenge is paramount to ensure that considerable ground for conducting CSA is provided. It has also been established for a long time that, in order to achieve some milestones or targets, there is a need for measurement as the foundation for such targets. This concept has found its way into CSA as well [14]. The yield of any practice to introduce the concept of sustainability in academic campuses will become substantiated with a philosophical basis and HEI stakeholders' indicator preference/localization toward sustainable campuses before assessing how much the academic organization has been able to achieve the desired results.

Currently, HEIs in Nigeria are some of the least ranked in the world, with few HEIs among the HEIs that are recognized in the world universities ranking. However, the increase in the number of public and private HEIs is one of the fastest in Africa due to the country's large population and high rate of urbanization. The population of students, teaching staff, and non-teaching staff is projected to continue to increase over the next few decades. Other challenges, which include but are not limited to an inefficient campus transportation system, pollution, urban sprawl, the lack of campus basic facilities and infrastructure, dysfunctional campus land uses, the degradation of the campus environment, and unsustainable campus production and consumption patterns, are also affecting various campuses. The desire to resolve these challenges is revealed in the 2009 Abuja Declaration (held in Nigeria) on sustainability in African higher education [15]. The participants of the declaration acknowledge the fact that sufficient attention on conducting, disseminating, or implementing sustainability research and practice is lacking in African HEIs. The declaration, therefore, encourages the HEIs in Africa to reassess their system of education in terms of sustainable development and conduct a campus sustainability performance assessment. Additionally, there is an absence of sustainability accounting information on the official websites of two Nigerian universities that are signatories to the Talloires Declaration [16].

Although Nigeria has been investing in the planning and development of its HEIs, there is a huge gap in the development of tools, techniques, frameworks, or metrics to measure the sustainability 
performance of these institutions. Evaluation and effectiveness appraisal reports on the already existing campus development policies are not available on the official websites of various designated departments. A review of the literature indicates a lack of research and data, and the non-availability of official statistics on campus sustainability in Nigeria. This shows that sustainability practices and reporting in Nigerian HEIs are largely neglected, and it is expected that campus sustainability performance will be very low. In short, the status of campus sustainability is unknown in Nigeria. For instance, despite the inclusion of a Nigerian private university amongst 1004 registered HEIs to utilize the Sustainability Tracking, Assessment, and Rating System (STARS) tool as of mid-2020, the university has neither participated in the appraisal process nor received a sustainability performance rating. This might because STARS was originally created for North American HEIs and not those in Sub-Saharan African countries. The challenge of data restriction due to financial demand on the part of the participating institutions could be another justification for the unknown state of their sustainability status [17].

Taking into account the lack of measurements and data on such an important issue, there is a real need to examine the sustainability performance of Nigerian campuses. Most importantly, there is the need for the development of an adaptive localized model to assess the campus-wide impacts of HEIs campuses on QOL, as well as to establish some appropriate policy recommendations for authorities concerning campus sustainability. The development of this model is timely and critical, as there is presently no availability of such a campus model performing these activities within the Nigerian and Sub-Saharan African countries context. In addressing these challenges, this paper aims at the development of a Modifiable Campus-wide Appraisal Model (MOCAM) for the sustainability of HEIs in Nigeria and other Sub-Saharan African countries with an unknown sustainability ranking.

\section{Comparing Existing CSA Tools}

During the developmental stages of the proposed appraisal model, the following criteria were utilized in selecting the existing CSA tools for content analysis and coverage evaluation. They are (i) indicator-based, (ii) English language-based, (iii) HEI focus-based, and (iv) document-based. A brief description of the selection criteria is provided below.

1. Indicator-based: Although there exists in the literature different approaches to appraising sustainability practices in HEIs, the authors adopted the indicator-based approach for the development of the proposed model and the assessment of the sustainability performance. This is in line with other scholars who prioritized indicator-based assessment over other approaches due to its better performance level, objectivity, measurability, and ease of outcome comparison [18]. As such, several CSA tools with appropriate and excellent appraisal procedures but designed with narrative or account assessment were excluded.

2. English language-based: Additionally, there are several CSA tools that were developed in non-English speaking countries or by non-English speaking developers. The authors only utilized tools whose content information is written in the English language. This is also in compliance with the selection criteria of researchers that have previously conducted CSA tool reviews [7]. Tools, such as the German Commission for UNESCO, the Conference of Rectors of Spanish Universities, and the tool developed in Colombia, were excluded.

3. HEI focus-based: Under this criterion, only tools that are designed specifically for the appraisal of sustainability practices, reporting, and ranking in HEIs are considered for selection. Assessment tools such as the Global Reporting Initiative (GRI), which is mostly utilized in appraising sustainability performance in corporate organizations although adaptable for HEIs, were excluded.

4. Document-based: Lastly, the selected tools have to be available in documents format such as technical manuals, reports, articles, etc. to allow for content evaluation, the extraction of sustainability indicators, and referencing. Tools such as Benchmarking Indicators 
Questions-Alternative University Appraisal (BIQ-AUA) and the Green Plan were excluded from the selected CSA tools due to the authors' inability to retrieve their document for reference.

At the end of this selection process, 13 existing CSA tools were selected, as shown in Table 1. To comprehend the differences that exist in the selected tools and gain an understanding of their adoption, applicability, and approach to addressing the gaps observed in the literature, the following four criteria were used as a basis for comparison. They are: (i) the weighting method, (ii) the theory/framework utilized, (iii) the social media platform utilized, (iv) the environmental-dimension with campus-wide and spatial-based (ECS) sustainability attributes utilized (see Table 1). A brief discussion of the comparison criteria and the need for their utilization in such a comparison is provided below.

(a) Weighting Methods: Campus planning and development decision-making involve the procedures that entail the selection of the best options from among many variables. The process of arriving at these best alternatives by decision-makers during campus-wide planning or environmental challenge mitigation is hugely associated with a myriad of setbacks in the real world. In the field of decision theory, the weighting method represents one of the paramount pillars and is mostly utilized in discerning the optimum approach from multiple alternatives [19]. Since the introduction of these methodological approaches, several techniques have been initiated to advance the field of decision theory and the weighting method. Examples of these methods include but are not limited to the simple multi-attribute rating technique, the analytic network process (ANP), the Technique for the Order of Prioritization by Similarity to Ideal Solution (TOPSIS), ratio estimation in magnitudes or deci-bells to rate alternatives which are non-dominated (REMBRANDT), and the analytic hierarchy process (AHP) [20]. Solutions to decision-making challenges in urban development and the built environment projects involving campus design and planning are mostly attained via the use of these approaches. Therefore, there is need for a comparison of the selected existing tools based on the weighting method.

(b) Theory/Framework Utilized: In the fields of urban planning and social sciences, research on a theoretical perspective is unquestionably a paramount one. A larger percentage of great scholars known in these fields are theoretical scholars. However, within the last decade, many planners and social scientists are now giving less attention to theory development and utilization, and studies based on quantitative research methods have become dominant. Some of the consequences of not adopting or incorporating a theoretical basis in CSA studies include but are not limited to (a) an inability to accumulate knowledge, (b) a lack of persistency, (c) an inability to differentiate different events, and (d) the utilization of the wrong methodology. It is also imperative for researchers that are using more than one method to identify and rectify all the various theoretical approaches before commencing on a CSA project/model development. In the field of campus planning, a theoretical approach that will assist in interpreting and organizing the development and utilization of an appraisal model is required to ensure that the field is advanced in a scholarly manner. To fill the identified research gap, this criterion was utilized in comparing the existing tools.

(c) Social Media Platform Utilized: The recent rapid expansion that is currently witnessed within the field of HEI planning and campus master plans, and the huge interest of many researchers in campus sustainability audit and appraisal requires the need for the adoption and incorporation of social media data, machine learning, deep learning, sentiment analysis, and artificial intelligence. During the first quarter of 2019, more than 3 billion people were reported to be active social media users in different parts of the world, with over 2 billion users operating all kinds of media activities on their mobile devices [21]. Recently, green campus and sustainable campus initiatives have been trending on social media, with a huge amount of user-generated content (UGC) that could be utilized in comprehending the campus sustainability indicators with local context preferences. Based on this development, utilizing and advancing the accuracy, volume, and precision analysis of the data from social media is a welcome idea. This is an opportunity for the contribution to knowledge and the closing of research gaps in the field of campus sustainability 
and development in developing countries if the massive amount of data from various platforms of social media is utilized. In this study, the social media classification by Mangold and his colleague was utilized for comparing the social media platform utilization for indicator selection, data empirical validation, or case studies [22].

(d) ECS Sustainability Attributes Utilized: This criterion compares the inclusion of ECS campus sustainability attributes in existing CSA tools to determine how integrating geographic information systems (GIS) and/or other spatial techniques into the indicator-based framework for campus sustainability could ameliorate the challenges of data availability and accessibility for CSA in developing countries. The provision of the spatial dimension, guidelines, and spatial techniques are paramount because the level of adoption of issues that are explicitly stated in the guidelines is higher than the implicit issues [23]. Most campuses of HEIs have a large campus area with different transportation modes, facilities, and infrastructures covering large areas of land and several spatial-based campus attributes. As such, there is need for this criterion for comparison.

Though Table 1 presents the summary of the comparison between the existing CSA tools, the content analysis and the coverage evaluation of the selected tools reveal the following:

In terms of the weighting methods, their utilization can influence the sustainability performance appraisal report, result visualization, comparison, or ranking of HEIs campuses after undergoing the appraisal process by various tools [5]. The review and comparison show non-utilization/specification or justification of the selected weighted methods in most of the tools. The weighting method gives room for the monitoring, review, and enhancement of the CSA tools via the regular repetition of the pair-wise comparison by experts. This shows that most of the existing tools are rigid, with a lack of flexibility/adaptability for use in a different context. Assessment tools are rigid when there is no weight assignment procedure and difficulties in adding or removing indicators [17]. However, TUR and AMAS utilized AHP allowing for flexibility and indicators' addition and removal.

Regarding the theory/framework utilized, a review of the extant literature reveals that sustainability is itself a complex process, and this complexity has led to disruption in the assessment of the sustainability of academic campuses due to their diverse nature. This problem can be overcome by providing the campus administrators with an assessment model, a standard gauge against which the performance can be monitored and evaluated as well as a theoretical basis that gives a general explanation of the process. The tools for CSA, like all other models, must possess a certain philosophical basis to streamline the assessment process. The comparison shows that most of the tools were driven by the limitations of the existing tools and the availability of sustainability indicators for HEIs. However, there was the utilization of a general system theory that delineates the important elements for comprehending various aspects or components of HEIs [25]. Also utilized by two of the existing tools is the PDCA cycle, also known as the Deming cycle, based on the principle of regular advancement effort to allow for incremental progress over a long period [25,27]. A quality management model and framework that ensures the connection between individual aspects to identify an efficient approach to address the impacts of indicators [27,29]. In summary, none of the tools used main social theories that allow for the continuous review of the sustainability concept and would have driven their approach in utilizing social media data, despite the boom of social media during the development stage of these tools. 
Table 1. Comparison of the selected appraisal tools.

\begin{tabular}{|c|c|c|c|c|c|c|}
\hline \multirow{2}{*}{ CSA Tool } & \multirow{2}{*}{ Weighting Method } & \multirow{2}{*}{ Theory/Framework } & \multirow{2}{*}{ Social Media } & \multicolumn{3}{|c|}{ ECS-Based Attribute } \\
\hline & & & & Category & Indicator & Sub-Indicator \\
\hline $\begin{array}{l}\text { Sustainability Assessment } \\
\text { Questionnaire [24] }\end{array}$ & - & - & - & 1 & - & - \\
\hline $\begin{array}{l}\text { Graphical Assessment of } \\
\text { Sustainability in University [18] }\end{array}$ & - & - & - & 1 & 1 & 6 \\
\hline Sustainable University Model [25] & - & $\begin{array}{c}\text { (i) General Systems Theory, } \\
\text { (ii) Benchmarking Process, } \\
\text { (iii) The Plan-Do-Check-Act } \\
\text { (PDCA) Cycle }\end{array}$ & - & 1 & 10 & - \\
\hline $\begin{array}{l}\text { University Environment } \\
\text { Management System [26] }\end{array}$ & - & - & - & 1 & 2 & 10 \\
\hline $\begin{array}{l}\text { Assessment Instrument for } \\
\text { Sustainability in Higher Education [27] }\end{array}$ & - & $\begin{array}{l}\text { (i) EFQM Excellence model, } \\
\text { (ii) The PDCA Cycle }\end{array}$ & - & 1 & 2 & - \\
\hline $\begin{array}{l}\text { Unit-based Sustainability } \\
\text { Assessment Tool [28] }\end{array}$ & - & - & - & - & 1 & - \\
\hline $\begin{array}{l}\text { Three dimension University } \\
\text { Ranking (TUR) [5] }\end{array}$ & AHP & - & Wikipedia & 1 & - & - \\
\hline DPSEEA-Sustainability index Model [29] & - & Linkage-based frameworks & - & - & 5 & 22 \\
\hline $\begin{array}{l}\text { Graz Model for Integrative } \\
\text { Development [30] }\end{array}$ & - & - & Facebook & - & - & - \\
\hline $\begin{array}{c}\text { Sustainable Campus } \\
\text { Assessment System [31] }\end{array}$ & - & - & - & 1 & 11 & 10 \\
\hline $\begin{array}{c}\text { Adaptable Model for Assessing } \\
\text { Sustainability in Higher Education } \\
\text { (AMAS) [17] }\end{array}$ & AHP & - & - & - & 1 & 5 \\
\hline $\begin{array}{l}\text { Green Metric-UI's GreenMetric } \\
\text { University Sustainability Ranking [32] }\end{array}$ & - & $\begin{array}{l}\text { Three E's Framework: } \\
\text { Environment, Economics, } \\
\text { Equity, and Education }\end{array}$ & - & 5 & 11 & - \\
\hline STARS [33] & - & - & $\begin{array}{c}\text { (i) Facebook, } \\
\text { (ii) Twitter, } \\
\text { (iii) Interactive blog }\end{array}$ & 1 & 6 & 12 \\
\hline
\end{tabular}


This study also advances the existing studies by reviewing and analyzing the coverage of social media and social data in the existing CSA tools. The results reveal that, despite the presence of indicators that seek to appraise HEIs' sustainability performance in communication, public participation, student involvement, etc., in most of the tools, social media platforms as means of achieving this sustainability performance were neither mentioned nor utilized in most of the tools. Social media usage was limited in the existing tools. This is despite the development of some of these tools in developed countries, where the utilization of different social media platforms is high. These findings are inconsistent with studies that show a strong correlation between social media usage and improvement in HEIs campuses' sustainability activities [34]. Lastly, the outcomes reveal an absence of ECS indicators in some of the tools and variations in their usage and selection. It was observed that these variations can lead to the difficulties in arriving at uniform appraisal ratings in several campuses. Therefore, there is need for a model for appraising different campuses across the geographic or local context with localization of the indicators to the relevance of each campus. This comparison reveals that humongous improvement can be adopted, utilized, or modified to fill the gaps identified in the literature in terms of the lack of or restricted access to data, choosing a set of indicators, and difficulties in indicator appraisal. With the integration of the GIS and/or other spatial software into the CSA spatial-based model, these challenges could be minimized.

In addressing the challenges of HEI campus sustainability in Nigeria with consideration of the gaps identified in the existing ranking, rating, and appraisal tools, the next section describes the proposed appraisal framework.

\section{Constructing the Appraisal Model}

In developing an appraisal model with campus-wide and spatial-based indicators that apply to different HEIs within the context of Nigeria and, by extension, other HEIs in Sub-Saharan African countries, the sequential stages depicted in Figure 1 were utilized. A brief description of these stages are provided as follows:

a. SMART Approach: The SMART (specific, measurable, achievable, relevant, and time-bound) approach is a goal attainment approach that has been used utilized in previous campus and management studies $[13,35]$. In this study, the approach was used to extensively explore the indicators (such as the striking balance between breadth of coverage and inclusion of indicators) in addition to the coverage evaluation approach.

b. Social Media Approach: This allows for the calibration of the CSA categories and indicators based on local context to ensure the selection that corresponds to the needs and nature of HEIs in Nigeria. This is achieved via the calibration of the indicators with SMART attributes with the social media UGC relating to campus sustainability awareness, engagement, and knowledge, etc., of the HEI stakeholders.

c. Attribute Relative Importance and Weights: Amongst the various techniques of weighting methods, AHP which was designed by Saaty [20] is the most highly used and has gained a high level of awareness in the building, planning, and construction industries, as well as the sustainable campus appraisal research area. Decision-making challenges in the area of designing, planning, and development of HEIs campuses involve a lot of complexity, complications, and uncertainties [36]. As such, making a concise and best decision in solving developmental projects in the area of the built environment is a necessity that should not be overlooked. Therefore, the choice of AHP in identifying relative importance and weights of selected attributes are due to several reasons, such as (i) the ability to make better and strategic built environment-related projects decisions [37], (ii) a higher level of consistency, (iii) selection of a perfect and most favorable option from amongst several alternatives during a multiple criteria decision process, and (iv) simplified communication using an index to display the overall ranking of an institution.

d. Visualize Result: To allow for the communication and comparison of the appraisal results that is conceivable by all HEI stakeholders, the appraisal outcome of the proposed model will be 
a spatial graphic support that aids the visual examination of HEI campuses. GIS, building information modeling (BIM), CityEngine, and or other related spatial tools are important in the campus-wide appraisal of HEI campuses; however, their usage is currently lagging in the existing CSA tools.

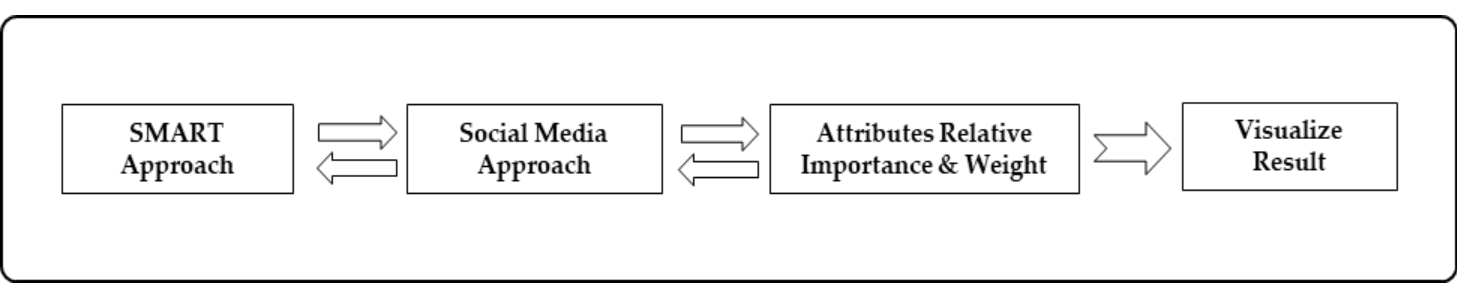

Figure 1. Roadmap to campus-wide sustainability appraisal.

\subsection{Identification and Verification of Attributes Reflecting and Matching the Nature of HEIs in Nigeria}

\subsubsection{SMART Approach}

The inclusion of measurable sustainability indicators based on value judgment has been extensively studied and supported in the extant literature [38], although the selected sustainability indicators for the appraisal process are recommended to be conducted within the context of objective principles. As such, the process of identifying indicators for sustainability performance models/projects should be carried out in a systematic, transparent, and most importantly participatory manner. In this study, while ensuring that the selected indicators have the capability of effectively appraising campus-wide sustainability performance with analytically sound outcomes, the selection process entails: first, the identification and extraction of a comprehensive list of indicators from the existing 13 CSA tools. Therefore, the environmental-dimension indicators with spatial-based and campus-wide attributes were selected to form an ECS broad list. This was followed by a filtering process based on the SMART approach $[13,35]$. The SMART approach ensures that the indicators selected for the CSA process possess the attributes briefly described below:

(i) Specific: The selected indicators should be stated unambiguously. They should clearly define the aspect of the campus-wide and environmental-dimension outcomes of the appraisal will be derived. They should be specified conceivably by HEI stakeholders.

(ii) Measurable: The selected indicators should possess a standardized unit of measurement to allow for comparison and statistical analysis obtained from numerical values selected.

(iii) Achievable: The selected indicators should possess the attributes that will ensure the attainment of overall appraise goals, objectives, outcomes, and deliverables.

(iv) Relevant: The selected indicators should have the capacity of attaining the local demands and the sustainability challenges of the institutions within the geographical region of the appraisal exercise.

(v) Time-bound: The selected indicators allow for periodic audits and continuous monitoring and review.

The indicators that do not meet these five SMART attributes were excluded from the sustainability performance of campus-wide sustainability.

\subsubsection{Social Media Approach}

The preferences of key or concern stakeholders on challenges affecting HEIs can be referred to as the perception of the public on the aspects of the sustainability activities on these campuses. They can also be referred to as the comments, assessment, evaluation, reactions, or sentiment of experts on campus conditions, resources, management practices, and sustainability indicators. It provides relevant contributions to the development of appraisal tools that incorporate the desires and direction 
of the end-users. These stakeholders' preferences can positively or negatively affect the campuses in aspects that include but are not limited to: (i) the winning of funds and grants; (ii) the attraction of sponsors, investors, and students; (iii) sustainability appraisal rating and ranking.

The determination of the preferences of concerned HEI stakeholders can be obtained through the satisfaction level of these stakeholders in terms of sustainability behaviors, awareness of campus sustainability activities, and similar topics. The need for the consideration of the awareness level and satisfaction of key stakeholders in management, operations, the urban/campus setting, infrastructure, environment, and transportation necessitates the carrying out of stakeholder preference. A literature review reveals that target group interviews, small group questionnaire surveys, important performance analysis, fuzzy TOPSIS, the analytic hierarchy process (AHP), expert opinion, and scoring constitute the major approaches to appraising stakeholders' preferences in HEI studies. In these methods, only a few key stakeholders are involved in the designing, planning, and development of HEIs. In the AMAS [17] CSA tool, eight local experts were consulted in identifying indicators with local priorities.

To incorporate local priorities, this study utilized a novel approach involving the UGC from the Twitter social media platform of official accounts of all universities in Nigeria. The UGC was mined using Python Library, while Elastic Stack was used for filtering, analyzing, and identifying only indicators that appear in the UGC, based on the campus sustainability awareness level of HEI stakeholders in Nigeria.

\subsection{Determination of CSA Attributes Relative Importance and Weights}

In this study, AHP was utilized in determining the localized attribute level of importance and their corresponding weights. In understanding the usage of AHP with spatial techniques, a comprehensive review of the existing literature reveals the connection between AHP and spatial-based information systems. An integrated approach that combined AHP with NetWeaver and spatial-based software was designed in Spain [39]. While the AHP was used for the determination of weights for the spatial based-indicators, the spatial-based software (ArcGIS) was utilized for the storage and performance of a certain spatial analysis. Another spatial-based software with AHP, utility theory, and an online analytical process was also utilized by Ahmad and teammates for the selection and the rating of selected variables level of importance [40]. They also ensure that a case study of how the integrated approach has been successfully applied was presented to reveal the reliability and validity of their approach.

Again, it was discovered that AHP was either utilized in addition to other theoretical approaches and methodology in ensuring a better outcome or as an independent method. This shows that the incorporation and/or the adoption of AHP in the field of campus planning, development, and assessment to ascertain the level of importance of variables is a welcome development. Although other weighting methods, such as TOPSIS, REMBRANDT, and ANP, produce reliable decision-making outcomes, however, AHP has a remarkable edge over them because they are more complicated, challenging, and protracted [37]. After the completion of the social media approach of environmental-dimension indicators with campus-wide and spatial-based attribute identification, experts with urban planning, designing, impact appraisal, etc., knowledge and skills registered with the Association of Town Planning Consultants of Nigeria (ATOPCON) were consulted for validation. This was followed by the development of a three-level hierarchy (Figure 2), with the overall goal of a campus-wide sustainability performance appraisal on the first level, followed by six category levels with 14 indicators applicable within the context of HEI campuses in Nigeria.

A pair-wise comparison survey based on Saaty's nine-point scale was carried out with 18 registered town planners across the six geopolitical zones of Nigeria. The pair-wise comparison survey allows for the transformation of verbal judgment to numeral values by ensuring the appropriation of weights to spatial-base sustainability categories and indicators. The outcomes reveal satisfying consistency ratios. Individual weight was aggregated to attain the overall weights of the categories and indicators 
concerning the overall focus of campus-wide sustainability performance appraisal based on the equation below.

$$
\mathrm{w}\left(C_{i j}\right)_{A}=\sum_{i j}^{N}\left[\mathrm{w}\left(C_{i j}\right)_{B j} \mathrm{w}\left(B_{j}\right)_{A}\right] .
$$

$\mathrm{w}\left(C_{i j}\right)_{A}$ is the weight of the indicator $C_{i j}$ with respect to the overall focus which is the campus-wide sustainability performance appraisal. $\mathrm{w}\left(C_{i j}\right)_{B j}$ is the local priority (weight) of $C_{i j}$ in relation to $B j$. However, $\mathrm{w}\left(B_{j}\right)_{A}$ is the local priority (weight) of indicator $\mathrm{i}$ in a group $\mathrm{j}$ in relation to $A$ [20].

To aid the dissemination of the outcomes, a spatial-based technique (i.e., GIS, BIM, etc.) could be utilized in visualizing the performance of the spatial-based and campus-wide indicators. Campus-wide comparison based on the environmental-dimensions could also be appraised using this spatial software.

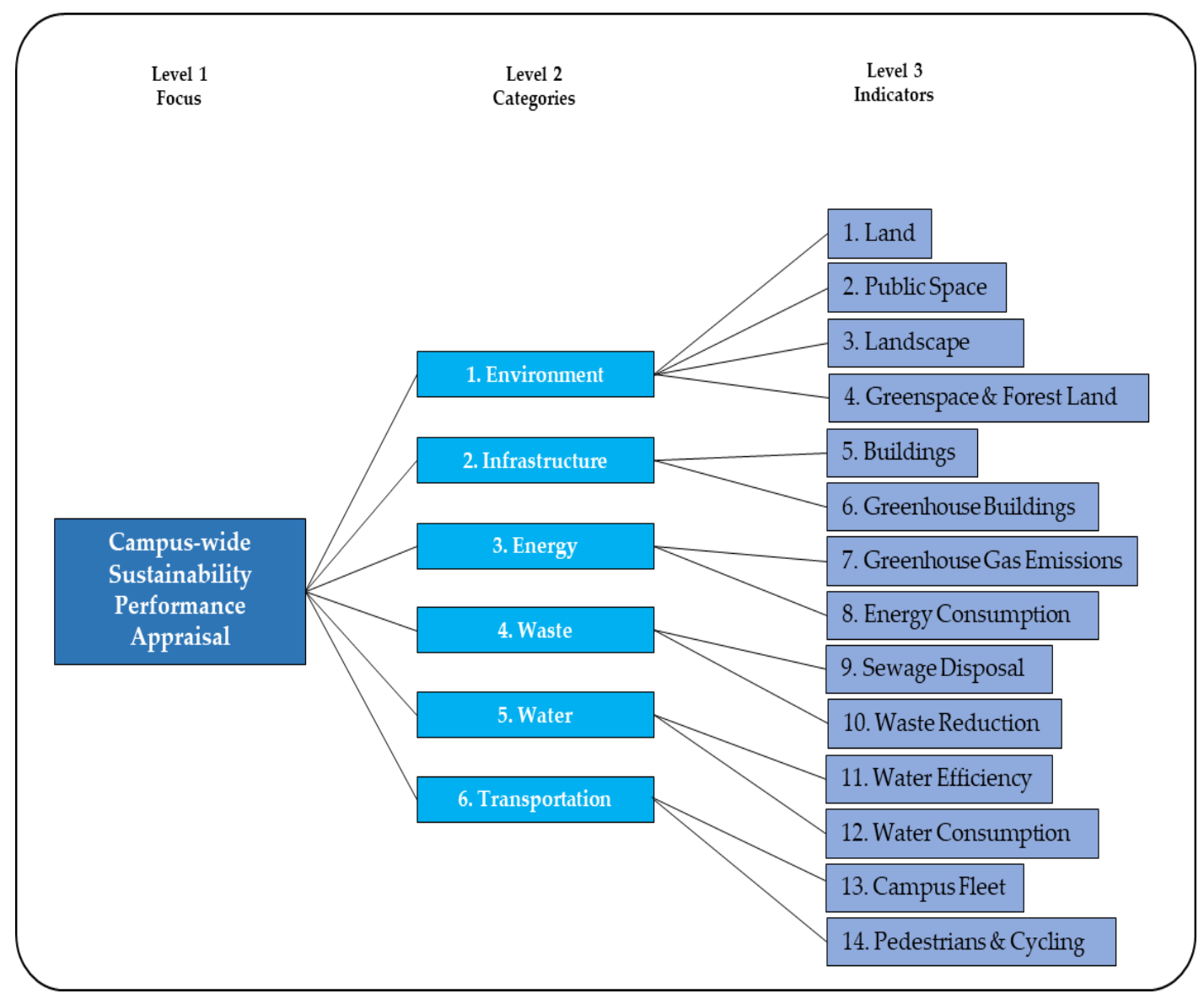

Figure 2. Appraisal hierarchy for relative importance.

\section{Modifiable Campus-wide Appraisal Model (MOCAM) for Sustainability in HEIs}

The review of the existing tools and the roadmap to constructing an appraisal model presented in Section 3 led to the development of a campus-wide model for appraising the sustainability performance of spatial-based attributes in HEIs campuses in Nigeria.

\subsection{The Model Theoretical Basis}

Due to the non-utilization of a theoretical basis that ensures the monitoring and appraisal of CSA using social media UGC, the authors adopted symbolic interactionism as a theoretical basis for appraising the sustainability in HEI campuses based on social media data. The theory has several applications on studies relating to CSA and framework development. Although many scholars 
have challenged the approach of symbolic interactionism claiming that it only focuses on broad and macro-sociological issues [41], this criticism has been rejected [42,43]. The application of the theory in several other academic disciplines [44], as well as other theories [45,46], has further provided justifications to debunk the claims that the theory could not be applied at micro-level and in other disciplines. Other scholars were also able to incorporate the epistemological assumptions of symbolic interactionism with other theories and other socio-cultural studies [47-50].

Another scholar claimed that the theory utilizes secondary and survey data to conduct statistical analysis as well as to conduct applied socio-cultural research that is policy-related [51]. This shows that symbolic interactionism theory has a lot of applicability in CSA research and technology-driven resources and tools, as well as artificial intelligence approaches, such as machine learning, deep learning, and sentiment analysis. The authors of this article are not in any way intending to claim the supremacy of the symbolic interactionism over other philosophical approaches, despite its adoption in this CSA study. The adoption of a social science theory such as symbolic interaction can serve as the beginning of innovative ways toward incorporating several related theoretical bases into the assessment of HEIs campuses in both the developed and the developing world involving huge social media information. Figure 3 below presents the incorporation of the theory as a theoretical basis into the appraisal of sustainability performance in HEIs.

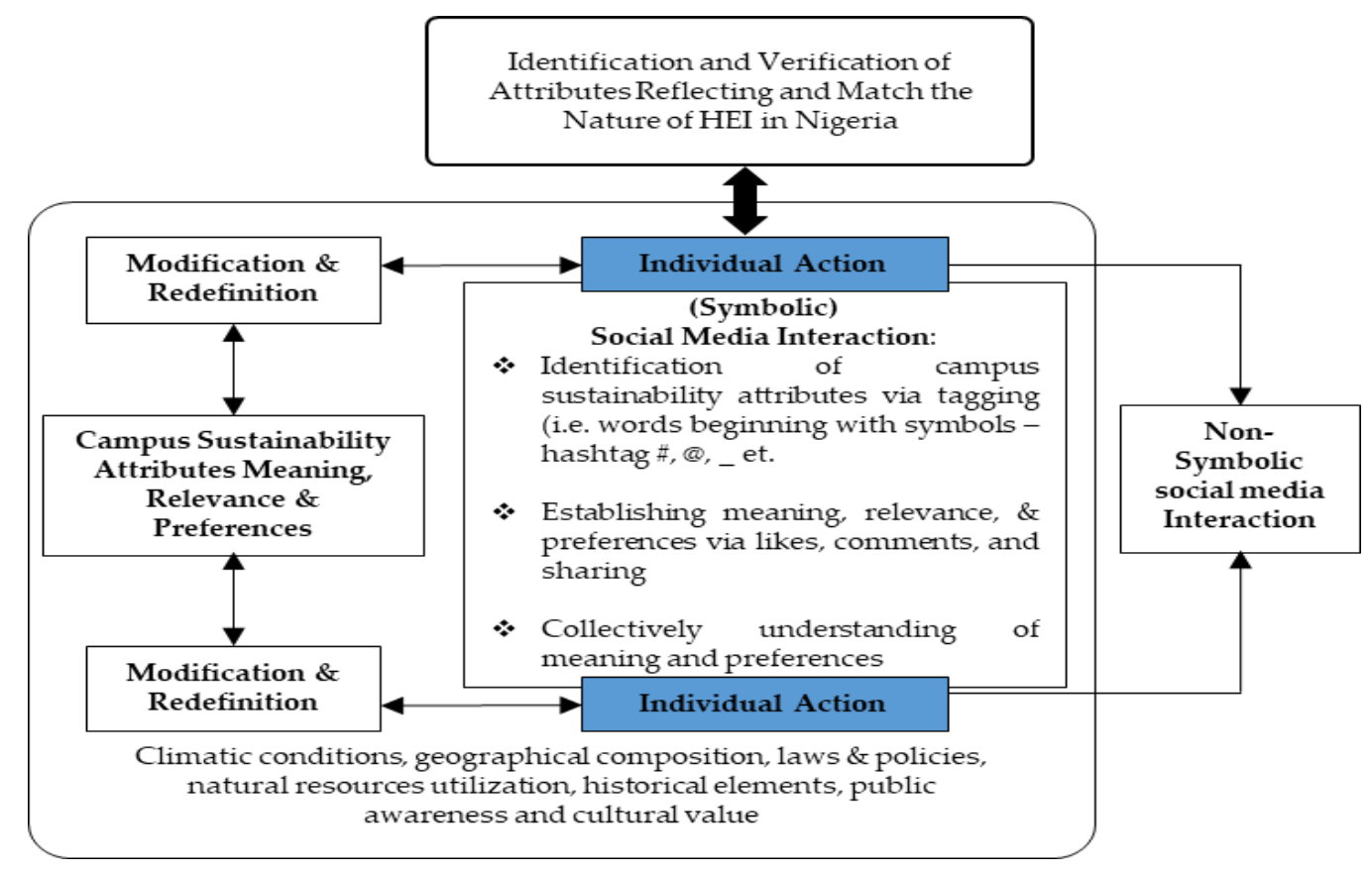

Figure 3. Theoretical basis of symbolic interactionism in campus sustainability appraisal

In this study, Twitter social media, which displays the concept of symbolic interactionism, was utilized. On Twitter, users are identified based on the perception of others. Therefore, the HEIs communities' users' behaviors and discussions on Twitter social media were studied by identifying the symbols (language) that are mostly used during the process of interactions. Twitter and several other social media channels use the tag symbols to allow users to actively participate in comments and posts such as green campus, sustainable campus, green university, university sustainability, etc. For instance, tagging informs the users at the receiving end of posts, comments, and pictures that $\mathrm{s} / \mathrm{he}$ has associated his or her self with. Examples of tags are but are not limited to hashtag (\#), @,//, _. Social media users use all these tags to interact with each other on various platforms. With the identification of several symbols of communication and interactions on Twitter, the authors utilized the @ symbols of all official twitter handles of universities in Nigeria to mine a huge volume of data and thereafter filtered it to identify the campus sustainability indicators that were mostly discussed online. 


\subsection{Different HEIs Context Adaptability, Continuous Improvement, Monitoring and Review}

The model is developed to allow for the modification (as depicted in Figure 4) of a campus-wide sustainability appraisal of different campuses within the Nigerian context and, by extension, that of other Sub-Saharan African nations.

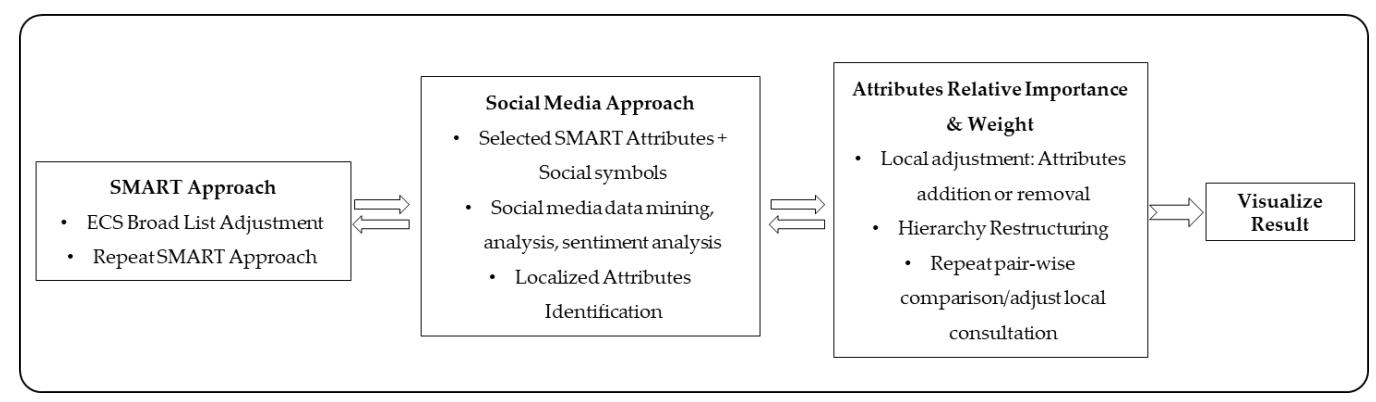

Figure 4. Modifiable campus-wide appraisal model for higher education institutions

AHP allows for continuous improvement, advancement, monitoring, and review by repeating the pair-wise comparison process with local experts. This is an improvement over most of the existing tools, which do not justify the selection and weighing process for appropriating relative weights. The SMART Approach can be easily repeated after an adjustment to the ECS broad list. The third major assumption of symbolic interactionism states that "meanings are assigned and modified through an interpretive process that is ever-changing, subject to redefinition, relocation, and realignments" [52] p.544. Because assigned meanings to the indicators of sustainability in HEIs on social media continue to change and modified, this gives a perfect justification for continuous monitoring and review of the CSA process. Unlike other appraisal techniques that fail to understand the need for modification of their frameworks or continue to conduct an appraisal regularly, the concept of symbolic interactionism gives a philosophical justification for engaging in such activities. This also provides evidence as to why several frameworks that did not pay attention to the incorporation of theories experience model errors, wrong methods, the inadequate selection of appropriate concepts, and the lack of persistence. The adoption of symbolic interactionism in campus sustainability will expand the comprehension of individual behaviors to the practice of sustainability in HEIs, especially via social media interactions. Human beings establish new meaning and advance ways of responding to stimuli interpretation, which makes them design a better future as a result of the process of interpreting meaning.

\subsection{AHP Results and Indicators' Campus-wide Measurement}

The completion of the relative importance and weights of the indicators and their corresponding categories process (discussed in Section 3) finalized the development of an appraisal model for the Nigerian context. The final categories and indicators weight derived from the local consultation based on pair-wise comparison AHP survey is present in Table 2. The results show that the transportation category and campus fleet indicators are the most important. Recall that the selected indicators for the model possess the SMART attributes, therefore they are all measurable to allow for the calculation of the indicators. Table 2 also contains the campus-wide indicators measurement approach for the actualization of the model within the Nigerian context. Campus-wide, spatial-based indicator vectors, and raster data types obtained from HEIs, campus maps, and aerial/satellite images will be geo-referenced via spatial technique software to allow for the implementation of the appraisal process. Spatial technique software will also be utilized to display the present sustainability status, in addition to the future scenario simulation. Online spatial technique application will further ensure public participation in the campus planning and appraisal process besides stakeholders' participation via social media platforms. 
Table 2. Analytic hierarchy process results and indicators' campus-wide measurement.

\begin{tabular}{|c|c|c|c|c|}
\hline Categories & Weight & Indicators & Weight & Campus-Wide Measurement \\
\hline \multirow{4}{*}{ Environment } & \multirow{4}{*}{0.1309} & Land & 0.0328 & \multirow{4}{*}{$\begin{array}{c}\text {-The acreage/area of green area, land, public space, } \\
\text { and public space in } \mathrm{m}^{2} . \\
\text {-Area of heat islands in } \mathrm{m}^{2} \text {. }\end{array}$} \\
\hline & & Public Space & 0.0437 & \\
\hline & & Landscape & 0.0211 & \\
\hline & & Greenspace and Forest Land & 0.0335 & \\
\hline \multirow[b]{2}{*}{ Infrastructure } & \multirow[b]{2}{*}{0.1234} & Buildings & 0.0911 & \multirow{2}{*}{$\begin{array}{c}\text {-Area of buildings, green building with Certified LEED, } \\
\text { natural heritage and physical structure in } \mathrm{m}^{2} \text {. } \\
\text {-Location of green buildings/buildings, natural heritage, } \\
\text { and physical structure. }\end{array}$} \\
\hline & & Green Buildings & 0.0237 & \\
\hline \multirow[t]{2}{*}{ Energy } & \multirow[t]{2}{*}{0.1156} & Greenhouse Gas Emissions & 0.0174 & \multirow{2}{*}{$\begin{array}{l}\text {-Location of renewable sources, greenhouse gas concentration, } \\
\text { emissions, effluents, and waste concentration. } \\
\text {-Energy consumption in kWh. } \\
\text {-Quantity of electricity per area of solar. } \\
\text {-Area and percent of buildings that generate greenhouse gases. } \\
\text {-Greenhouse gases in } \mathrm{CO}_{2} \text { equivalent. }\end{array}$} \\
\hline & & Energy Consumption & 0.0891 & \\
\hline \multirow[b]{2}{*}{ Waste } & \multirow[b]{2}{*}{0.1630} & Sewage Disposal & 0.0398 & \multirow{2}{*}{$\begin{array}{l}\text {-Amount of waste disposal and reduction in } \mathrm{m}^{3} \text { and metric tons. } \\
\text {-Location of sewage disposal. } \\
\text {-Area of waste collection in } \mathrm{m}^{2} .\end{array}$} \\
\hline & & Waste Reduction & 0.1231 & \\
\hline \multirow[b]{2}{*}{ Water } & \multirow[b]{2}{*}{0.2005} & Water Efficiency & 0.0510 & \multirow{2}{*}{$\begin{array}{l}\text {-Amount of water in } \mathrm{m}^{3} / \text { litres/ } / \mathrm{ft}^{3} / \text { gallons. } \\
\text {-Locations of water supply. } \\
\text {-Area of water supply. }\end{array}$} \\
\hline & & Water Consumption & 0.1490 & \\
\hline \multirow{2}{*}{ Transportation } & \multirow{2}{*}{0.2665} & Campus Fleet & 0.2016 & \multirow{2}{*}{$\begin{array}{l}\text {-The dimensions (1D, 2D, 3D) of cycling, pedestrian, ramps, } \\
\text { and campus route, in } \mathrm{m} / \mathrm{km} / \mathrm{km}^{2} \text {. }\end{array}$} \\
\hline & & Pedestrians and Cycling & 0.0654 & \\
\hline
\end{tabular}




\section{Conclusions and Future Research}

Research is a systematic process, and sequential steps are required to achieve the goals and objectives outlined at the initiation of such endeavor. As such, a background study was carried out on (i) CSA tools, (ii) multi-criteria decision-making methods (MCDM), (iii) main societal-based social science theories, and (iv) social media platforms and scrapping tools. The systematic process involves the comprehensive review of more than 20 existing CSA tools, 5 main social theories, several social media platforms and data mining tools, as well as the major MCDM used in CSA. These processes and steps were carried out to achieve the aim of this study, which is the development of a modifiable campus-wide appraisal model (MOCAM) for a comprehensive spatial-based information and appraisal framework for policymakers. The identified research gaps in the literature were addressed, and the model was successfully created to address these challenges.

The background knowledge assists in establishing the current research gap that led to (a) the adoption of symbolic interactionism as the proposed model's theoretical basis; (b) the selection of existing 13 CSA tools for the comparison and eventual identification of spatial-based, campus-wide, and environmental-dimension categories and indicators; (c) the adoption of Twitter social media platform, the Elastic Stack scrapping tool, and eventual mining of UGC from the selected social media platform of HEIs for the identification of localized sustainability attributes based on the awareness and involvement of stakeholders; (d) the adoption of the AHP weighting method to determine the attributes' relative importance and weights. CSA, with an approach involving Twitter social media data with a symbolic interactionist perspective, is rare in literature, as such revealing the novelty of this research. The implications of this study for policymakers, the managers of HEIs, and scholars in urban sustainability appraisal is the study's approach that has the potential of creating a better method for conducting CSA, especially with the use of open-source software (Elastic stack) that does not require any customization.

The roadmap to campus-wide sustainability appraisal (Figure 1) and a modifiable model (Figure 4) guide in developing efficient, significant, innovative methods for conducting CSA in Nigeria HEIs. This article extensively discusses the three stages involved (i.e., SMART Approach, Social Media Approach, and Attributes Relative Importance and Weights). Future studies on the fourth stage (i.e., Visualize Result) that will involve the selected campus sustainability indicators to conduct a campus-wide dimensional simulation modeling seem appropriate in order to visualize the impact of the indicators with a high and low level of importance. Future research should also ensure that the identified localized indicators via the social media approach are thereafter subjected to machine learning and sentiment analysis using Azure machine learning to identify the users' negative, positive, and neutral orientations and behaviors towards the level of sustainability across the HEI campuses in Nigeria. Based on the tenets of symbolic interactionism, campus policymakers would be able to concentrate on how HEIs stakeholders and practitioners attached meaning to individual campus sustainability behaviors based on several factors. Finally, future studies that will incorporate more social media data from both official and unofficial Twitter accounts and a Twitter account set up specifically to address these happenings in Nigerian HEIs should be conducted.

Author Contributions: Y.A.A. and E.H.W.C. both conceptualized this article. Y.A.A. carried out the investigation, methodology, formal analysis, and the writing-original draft preparation, review, and editing. E.H.W.C., Y.S., and C.K.C. were actively involved in the supervision of the research. All the authors have read and agreed to the published version of the manuscript.

Funding: This research received no external funding.

Acknowledgments: The Hong Kong Polytechnic University's Research Institute for Sustainable Urban Development (RISUD) and the Department of Building and Real Estate are acknowledged for providing the research environment to the corresponding author. The corresponding author is supported by Hong Kong Polytechnic University International Postgraduate Scholarship.

Conflicts of Interest: The authors declare no conflict of interest. 


\section{References}

1. De Paula Arruda Filho, N.; Przybylowicz Beuter, B.S. Faculty sensitization and development to enhance responsible management education. Int. J. Manag. Educ. 2020, 18, 100359. [CrossRef]

2. Brundtland Commission. Our Common Future: World Environment and Development; Oxford University Press: Oxford, UK, 1987.

3. UNESCO. Educating for a Sustainable Future: A Transdisciplinary. Available online: https://unesdoc.unesco. org/ark:/48223/pf0000110686 (accessed on 22 August 2020).

4. Cortese, A.D. The Critical Role of Higher Education in Creating a sustainable Future. Plan. High. Educ. 2003, 31, 15-22. [CrossRef]

5. Lukman, R.; Krajnc, D.; Glavič, P. University ranking using research, educational and environmental indicators. J. Clean. Prod. 2010, 18, 619-628. [CrossRef]

6. De Matos Pedro, E.; Leitão, J.; Alves, H. Bridging intellectual capital, sustainable development and quality of life in higher education institutions. Sustainability 2020, 12, 479. [CrossRef]

7. Alghamdi, N.; Den Heijer, A.; De Jonge, H. Assessment tools' indicators for sustainability in universities: An analytical overview. Int. J. Sustain. High. Educ. 2017, 18, 84-115. [CrossRef]

8. Ceulemans, K.; Molderez, I.; Van Liedekerke, L. Sustainability reporting in higher education: A comprehensive review of the recent literature and paths for further research. J. Clean. Prod. 2015, 106, 127-143. [CrossRef]

9. Kamal, A.; Asmuss, M. Benchmarking tools for assessing and tracking sustainability in higher educational institutions. Int. J. Sustain. High. Educ. 2013, 14, 449-465. [CrossRef]

10. Shriberg, M. Assessing Sustainability: Criteria, Tools, and Implications. In Higher Education and the Challenge of Sustainability; Springer: Berlin/Heidelberg, Germany, 2004; pp. 71-86. [CrossRef]

11. Sonetti, G.; Lombardi, P.; Chelleri, L. True green and sustainable university campuses? Toward a clusters approach. Sustainability 2016, 8, 83. [CrossRef]

12. Yarime, M.; Tanaka, Y. The Issues and Methodologies in Sustainability Assessment Tools for Higher Education Institutions: A Review Journal of Education for Sustainable. J. Educ. Sustain. Dev. 2012, 6, 63-77. [CrossRef]

13. Alshuwaikhat, H.M.; Abubakar, I.R.; Aina, Y.A.; Adenle, Y.A.; Umair, M. The development of a GIS-based model for campus environmental sustainability assessment. Sustainability 2017, 9, 439. [CrossRef]

14. Shriberg, M. Institutional assessment tools for sustainability in higher education: Strengths, weaknesses, and implications for practice and theory. Int. J. Sustain. High. Educ. 2002, 3, 254-270. [CrossRef]

15. AAU. Abuja Declaration on Sustainable Development in Africa: The Role of Higher Education. In Proceedings of the 12th General Conference of Association of African Universities, Abuja, Nigeria, 4-9 May 2009; p. 2. [CrossRef]

16. Khan, T. Sustainability accounting courses, Talloires Declaration and academic research. Int. J. Sustain. High. Educ. 2013, 14, 42-55. [CrossRef]

17. Gomez, F.U.; S-Navarrete, C.; Lioi, S.R.; Marzuca, V.I. Adaptable model for assessing sustainability in higher education Adaptable Model for Assessing Sustainability. J. Clean. Prod. 2015, 107, 475-485. [CrossRef]

18. Lozano, R. A tool for a Graphical Assessment of Sustainability in Universities (GASU). J. Clean. Prod. 2006, 14, 963-972. [CrossRef]

19. Huang, T.C.K.; Chen, Y.L.; Chang, T.H. A novel summarization technique for the support of resolving multi-criteria decision making problems. Decis. Support Syst. 2015, 79, 109-124. [CrossRef]

20. Saaty, R.W. The Analytic Hierarchy Process-What and How It Is Used. Math. Model. 1987, 9, 161-176. [CrossRef]

21. Hasnat, M.; Faghih-imani, A.; Eluru, N.; Hasan, S. Destination choice modeling using location-based social media data. J. Choice Model. 2019, 31, 22-34. [CrossRef]

22. Mangold, W.G.; Faulds, D.J. Social media: The new hybrid element of the promotion mix. Bus. Horiz. 2009, 52, 357-365. [CrossRef]

23. Urbanski, M.; Filho, W.L. Measuring sustainability at universities by means of the Sustainability Tracking, Assessment and Rating System (STARS): Early findings from STARS data. Environ. Dev. Sustain. 2015, 17, 209-220. [CrossRef]

24. ULSF. Sustainability Assessment Questionnaire (SAQ) for Colleges and Universities. Available online: http://ulsf.org/wp-content/uploads/2015/06/SAQforHigherEd09.pdf (accessed on 22 August 2020). 
25. Velazquez, L.; Munguia, N.; Platt, A.; Taddei, J. Sustainable university: What can be the matter? J. Clean. Prod. 2006, 14, 810-819. [CrossRef]

26. Alshuwaikhat, H.M.; Abubakar, I. An integrated approach to achieving campus sustainability: Assessment of the current campus environmental management practices. J. Clean. Prod. 2008, 16, 1777-1785. [CrossRef]

27. Roorda, N.; Rammel, C.; Waara, S.; Fra Paleo, U. AISHE 2.0 Manual - English Edition. Available online: https://www.researchgate.net/publication/327551379_AISHE_20_Manual_-_English_Edition (accessed on 22 August 2020).

28. Muchaiteyi, T.; Heila, L.-S. Unit-Based Sustainability Assessment Tool-A Resource Book to Complement the UNEP Environment and Sustainability in African Universities Partnership. Available online: https:// wedocs.unep.org/bitstream/handle/20.500.11822/11283/USAT_tool.pdf?sequence=1\&isAllowed=y (accessed on 22 August 2020).

29. Waheed, B.; Khan, F.I.; Veitch, B. Developing a quantitative tool for sustainability assessment of HEIs. Int. J. Sustain. High. Educ. 2011, 12, 355-368. [CrossRef]

30. Mader, C. Sustainability process assessment on transformative potentials: The Graz Model for Integrative Development. J. Clean. Prod. 2013, 49, 54-63. [CrossRef]

31. Hokkaido University. Sustainable Campus Assessment System. Available online: http://www.eauc.org.uk/ theplatform/sustainable_campus_assessment_system (accessed on 22 August 2020).

32. Universitas Indonesia. Guideline UI GreenMetric World University Ranking 2019. Available online: http://greenmetric.ui.ac.id/wp-content/uploads/2015/07/UI_GreenMetric_Guideline_2019_English_ 1.2.pdf (accessed on 22 August 2020).

33. Association for the Advancement of Sustainability in Higher Education. Stars Technical Manual. Available online: https://stars.aashe.org/wp-content/uploads/2019/07/STARS-2.2-Technical-Manual.pdf (accessed on 22 August 2020).

34. Zachos, G.; Anagnostopoulos, I. Social Media Use in Higher Education: A Review. Educ. Sci. 2018, 8, 194. [CrossRef]

35. Shahin, A.; Mahbod, M.A. Prioritization of key performance indicators: An integration of analytical hierarchy process and goal setting. Int. J. Product. Perform. Manag. 2007, 56, 226-240. [CrossRef]

36. Chan, A.P.C.; Chan, D.W.M.; Yeung, J.F.Y. Overview of the application of "fuzzy techniques" in construction management research. J. Constr. Eng. Manag. 2009, 135, 1241-1252. [CrossRef]

37. Jato-espino, D.; Castillo-lopez, E.; Rodriguez-hernandez, J.; Canteras-jordana, J.C. Automation in Construction A review of application of multi-criteria decision making methods in construction. Autom. Constr. 2014, 45, 151-162. [CrossRef]

38. Shields, D.J.; Šolar, S.V.; Martin, W.E. The role of values and objectives in communicating indicators of sustainability. Ecol. Indic. 2002, 2, 149-160. [CrossRef]

39. Ruiz, M.C.; Romero, E.; Pérez, M.A.; Fernández, I. Automation in Construction Development and application of a multi-criteria spatial decision support system for planning sustainable industrial areas in Northern Spain. Autom. Constr. 2012, 22, 320-333. [CrossRef]

40. Ahmad, I.; Azhar, S.; Lukauskis, P. Development of a decision support system using data warehousing to assist builders/developers in site selection. Autom. Constr. 2004, 13, 525-542. [CrossRef]

41. Reynolds, L.T. Interactionism: Exposition and Critique; Rowman \& Littlefield: Oxford, UK, 1993.

42. Tucker, C.W.; Blumer, H.; Tucker, C.W. Herbert Blumer: A Pilgrimage with Pragmatism. Symb. Interact. 1988, 11, 99-124. [CrossRef]

43. Maines, D.R. Myth, Text, and Interaction Complicity in the Neglect of Blumer's Macrosociology. Symb. Interact. 1988, 11, 43-57. [CrossRef]

44. Altheide, D.L. Symbolic Interaction and 'Uses and Gratification': Towards a Theoretical Integration. Communications 2009, 11, 73-82. [CrossRef]

45. Couch, C.J. Symbolic Interaction and Generic Sociological Principles. Symb. Interact. 1984, 7, 1-13. [CrossRef]

46. Young, T.R. Chaos Theory and Symbolic interation Theory: Poetics for the Postmodern Sociologist. Symb. Interact. 1991, 14, 321-334. [CrossRef]

47. Ashley, D. Marx and the Category of Individuality' in Communist Society. Symb. Interact. 1985, 8, 63-83. [CrossRef]

48. Batiuk, M.E.; Sacks, H.L. George Herbert Mead and Karl Marx: Exploring Consciousness and Community. Symb. Interact. 1981, 4, 207-223. [CrossRef] 
49. Corsaro, W.A.; Rizzo, T.A. Discussione and Friendship: Socialization processes in the peer culture of Italian nursery school children. Am. Sociol. Rev. 1988, 53, 879-894. [CrossRef]

50. Winter, J.A.; Goldfield, E.C. Caregiver-Child Interaction in the Development of Self: The Contributions of Vygotsky, Bruner, and Kaye to Mead's Theory. Symb. Interact. 1991, 14, 433-447. [CrossRef]

51. Fine, G.A. Ten Lies of Ethnography: Moral dilemmas of field research. J. Contemp. Ethnogr. 1993, 22, $267-294$. [CrossRef]

52. Shalin, D.N. The Romantic Antecedents of Meadian Social Psychology. Symb. Interact. 1984, 7, 43-65. [CrossRef]

(C) 2020 by the authors. Licensee MDPI, Basel, Switzerland. This article is an open access article distributed under the terms and conditions of the Creative Commons Attribution (CC BY) license (http://creativecommons.org/licenses/by/4.0/). 